\title{
OPEN Peripapillary retinal nerve fiber layer thickness in patients with unilateral retinal vein occlusion
}

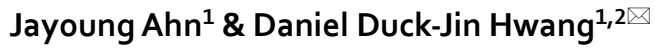

This study evaluated longitudinal changes in peripapillary retinal nerve fiber layer (pRNFL) thickness in eyes affected with branch and central retinal vein occlusion (BRVO and CRVO, respectively) and fellow eyes. This retrospective case-control study included patients with newly diagnosed unilateral BRVO (46 patients) or unilateral CRVO (27 patients). The control group included 48 patients without abnormal findings on the fundus examination. Global and all-sector PRNFL thicknesses were greater in eyes with BRVO and CRVO than in fellow eyes at baseline; however, at 24 months, this difference remained only in the temporal sector of eyes affected with CRVO. Although the global pRNFL thicknesses of the fellow eyes in the BRVO and CRVO groups decreased significantly at 24 months compared to baseline $(p=0.001$ and $p=0.011$, respectively), there was no significant difference in the normal control group $(p=0.824)$. The global, inferior temporal, and inferior nasal $p R N F L$ thicknesses at 12 and 24 months were significantly lower in the fellow eyes of the CRVO group than in those of the BRVO and normal control groups. The fellow eyes of patients with BRVO and CRVO suffered a significant reduction in PRNFL thickness compared to normal controls, indicating that they are susceptible to pRNFL damage.

Retinal vein obstruction (RVO) is the second most common disease following diabetic retinopathy among retinal vascular diseases that cause vision loss ${ }^{1}$. RVO is classified as branch retinal vein occlusion (BRVO) or central retinal vein occlusion (CRVO) according to the location of the occluded vein ${ }^{2}$, with BRVO being four to six times more common than $\mathrm{CRVO}^{3-6}$.

The prevalence of glaucoma is higher in patients with RVO than in the general population ${ }^{7,8}$. The mean intraocular pressure (IOP) is reportedly higher in patients with RVO than in normal controls, and it has been hypothesized that elevated IOP results in blood vessel compression and subsequent intimal proliferation, leading to $\mathrm{RVO}^{9,10}$. Additionally, pathophysiological vascular abnormalities caused by systemic diseases such as hypertension and diabetes induce both glaucomatous optic neuropathy and $\mathrm{RVO}^{11-16}$, suggesting that insulin resistance and autoregulatory dysfunction may be the causes of both diseases ${ }^{17}$.

To confirm the association between RVO and glaucoma, several previous studies have investigated the peripapillary retinal nerve fiber layer (pRNFL) ${ }^{14,18-22}$. It has been reported that, two years after unilateral BRVO diagnosis, the pRNFL thickness in the affected eye is thinner than that of the normal fellow eye ${ }^{19}$. In a study that aimed to confirm the hypothesis that RVO and glaucoma share systemic vascular abnormalities, the pRFNL thickness was thinner in the normal fellow eyes of patients with unilateral RVO than in those of normal controls ${ }^{14,20,21}$.

However, previous studies have analyzed either BRVO and CRVO patients together ${ }^{14,20,22}$ or exclusively BRVO patients ${ }^{18,19,21}$. Kim et al. ${ }^{14}$ classified RVO according to the location of the occluded vein as arteriovenous crossing RVO (AV-RVO), optic nerve site RVO (ON-RVO), or optic nerve site RVO with optic nerve swelling (ONHSRVO), to subsequently perform a subgroup analysis; they found no difference in the pRNFL thickness between the AV-RVO and ON-RVO groups. However, given that this was a cross-sectional study and, therefore, focused solely on the moment of diagnosis, follow-up changes were not included. Furthermore, patients with ONHSRVO (five eyes) were excluded from analysis because of the small sample size.

Longitudinal comparisons of pRNFL thickness in BRVO and CRVO have not been reported to date, and the difference in the degree of glaucomatous damage between the two diseases is unknown. Therefore, this study

${ }^{1}$ Department of Ophthalmology, Hangil Eye Hospital, 35 Bupyeong-daero, Bupyeong-gu, Incheon 21388, Korea. 'Department of Ophthalmology, Catholic Kwandong University College of Medicine, Incheon, Korea. ${ }^{\square}$ email: daniel.dj.hwang@gmail.com 


\begin{tabular}{|l|l|l|l|l|}
\hline & BRVO & CRVO & Controls & p-value \\
\hline Patients & 46 & 27 & 48 & \\
\hline Age (years) & $63.20 \pm 10.02$ & $65.19 \pm 15.11$ & $63.44 \pm 10.31$ & $0.753^{\mathrm{a}}$ \\
\hline Sex & & & & $0.216^{\mathrm{b}}$ \\
\hline Male & 14 & 12 & 12 & \\
\hline Female & 32 & 15 & 36 & \\
\hline Affected eye & & & & $0.384^{\mathrm{b}}$ \\
\hline OD & 24 & 10 & 25 & \\
\hline OS & 22 & 17 & 23 & \\
\hline Systemic disease & & & & \\
\hline Hypertension & 21 & 15 & 25 & $0.685^{\mathrm{b}}$ \\
\hline Diabetes & 9 & 9 & 8 & $0.222^{\mathrm{b}}$ \\
\hline
\end{tabular}

Table 1. Baseline patient characteristics. Values are presented as the number or mean \pm standard deviation. $B R V O$ branch retinal vein occlusion, $C R V O$ central retinal vein occlusion, $O D$ right eye, $O S$ left eye. ${ }^{a}$ p-value derived from a one-way analysis of variance. ${ }^{\mathrm{b}} \mathrm{p}$-value derived from Pearson's chi-square test.

aimed to compare longitudinal changes in pRNFL thickness between the affected and fellow eyes of patients with unilateral BRVO and unilateral CRVO.

\section{Results}

We included 92 eyes of 46 patients with unilateral BRVO, 54 eyes of 27 patients with unilateral CRVO, and 48 eyes of 48 normal controls. Based on the horizontal raphe, 30 eyes had superior BRVO, and 16 eyes had inferior BRVO. There were no significant differences in baseline characteristics among the three groups (Table 1).

During the study period, $2.46 \pm 2.20$ intravitreal anti-vascular endothelial growth factor injections were administered to the affected eyes of patients with BRVO, and $3.74 \pm 3.78$ injections were administered to the affected eyes of patients with CRVO. The number of injections was not significantly different between the BRVO and CRVO groups $(\mathrm{p}=0.115$, derived from independent samples $t$-test). Scatter laser photocoagulation was performed in 5 of the affected eyes of patients with BRVO. In patients with CRVO, pan-retinal laser photocoagulation was performed in 9 of the affected eyes, and scatter laser photocoagulation was performed in 1 eye.

pRNFL thickness in the BRVO group. The global and all-sector pRNFL thicknesses of the affected eyes decreased significantly at 24 months compared to baseline (Table 2). In the fellow eyes, only the global pRNFL thickness decreased significantly at 24 months $(\mathrm{p}=0.001)$.

At baseline, the global and all-sector pRNFL thicknesses were significantly greater in the affected eyes than in the fellow eyes. The temporal sector pRNFL thickness of the affected eyes was greater than that of the fellow eyes at 6 and 12 months $(p=0.002$ and $p=0.013$, respectively). In contrast, the superior temporal pRNFL thickness was significantly lower in the affected eyes at 12 and 24 months ( $\mathrm{p}=0.048$ and $\mathrm{p}=0.007$, respectively).

pRNFL thickness in the CRVO group. The global and all-sector pRNFL thicknesses of the affected eyes decreased significantly at 24 months compared to the baseline (Table 3 ). Fellow eyes showed a significant decrease in global, superior temporal sector, and inferior temporal sector pRNFL thicknesses at 24 months $(\mathrm{p}=0.011, \mathrm{p}=0.003$, and $\mathrm{p}=0.022$, respectively).

At baseline, the global and all-sector pRNFL thicknesses were significantly greater in the affected eyes than in the fellow eyes. The global pRNFL thickness was greater in the affected eyes than in the fellow eyes by 12 months. The temporal sector pRNFL thickness was greater in the affected eyes than in the fellow eyes throughout the entire 24-month study period. The inferior temporal sector, inferior nasal sector, and nasal sector pRNFL thicknesses were significantly greater in the affected eyes than in the fellow eyes at 6 months $(\mathrm{p}=0.002, \mathrm{p}=0.025$, and $\mathrm{p}=0.026$, respectively)

Comparison of pRNFL thickness between the fellow eyes of patients with BRVO, CRVO, and normal controls. In the normal controls, there were no significant differences in global or all-sector pRNFL thicknesses at 24 months compared to baseline (Table 4). Additionally, there were no differences among the three groups regarding pRNFL thickness in any sector at baseline.

There were no significant differences in the global or all-sector pRNFL thicknesses of the normal controls compared to the fellow eyes of patients with BRVO at any of the visits. However, compared with normal controls, pRNFL thicknesses in the global, inferior temporal, and inferior nasal sectors at 12 and 24 months were significantly lower in the fellow eyes of patients with CRVO. When comparing fellow eyes in BRVO and CRVO, the latter presented with a lower pRNFL thickness in the global, inferior temporal, and inferior nasal sectors at 12 and 24 months.

The changes in global, superior temporal sector, and inferior nasal sector pRNFL thicknesses over time were significantly greater in the fellow eyes of patients with CRVO than in normal controls $(\mathrm{p}=0.045, \mathrm{p}=0.050$, and $\mathrm{p}=0.014$, respectively) (Fig. 1). Additionally, the changes in global, inferior temporal sector, and inferior nasal 


\begin{tabular}{|c|c|c|c|}
\hline & Affected eye & Fellow eye & p-value ${ }^{a}$ \\
\hline \multicolumn{4}{|c|}{ Global pRNFL } \\
\hline Baseline & $119.15 \pm 17.71$ & $104.52 \pm 10.46$ & $<0.001^{*}$ \\
\hline 6th month & $105.76 \pm 11.54$ & $104.07 \pm 10.58$ & 0.179 \\
\hline 12th month & $103.70 \pm 12.33$ & $103.87 \pm 10.33$ & 0.899 \\
\hline 24th month & $101.60 \pm 13.32$ & $103.35 \pm 10.21$ & 0.159 \\
\hline p-value ${ }^{\mathrm{b}}$ & $<0.001^{*}$ & $0.001^{*}$ & \\
\hline \multicolumn{4}{|c|}{ Superior temporal sector $\mathrm{pRNFL}$} \\
\hline Baseline & $161.28 \pm 31.33$ & $144.35 \pm 22.64$ & $0.001^{*}$ \\
\hline 6th month & $140.84 \pm 30.26$ & $145.13 \pm 21.71$ & 0.359 \\
\hline 12th month & $135.63 \pm 32.48$ & $145.04 \pm 21.67$ & $0.048^{*}$ \\
\hline 24th month & $130.19 \pm 34.54$ & $143.74 \pm 21.11$ & $0.007^{*}$ \\
\hline p-value ${ }^{\mathrm{b}}$ & $<0.001^{*}$ & 0.546 & \\
\hline \multicolumn{4}{|c|}{ Temporal sector pRNFL } \\
\hline Baseline & $101.15 \pm 31.00$ & $76.85 \pm 12.85$ & $<0.001^{*}$ \\
\hline 6th month & $82.53 \pm 14.69$ & $75.87 \pm 12.32$ & $0.002^{*}$ \\
\hline 12th month & $81.37 \pm 16.24$ & $75.78 \pm 11.86$ & $0.013^{*}$ \\
\hline 24th month & $78.71 \pm 11.83$ & $75.67 \pm 11.75$ & 0.103 \\
\hline p-value ${ }^{\mathrm{b}}$ & $<0.001^{*}$ & 0.084 & \\
\hline \multicolumn{4}{|c|}{ Inferior temporal sector $\mathrm{pRNFL}$} \\
\hline Baseline & $167.30 \pm 40.40$ & $151.26 \pm 19.36$ & $0.004^{*}$ \\
\hline 6th month & $149.71 \pm 32.00$ & $152.29 \pm 17.25$ & 0.564 \\
\hline 12th month & $148.22 \pm 31.46$ & $151.93 \pm 17.34$ & 0.449 \\
\hline 24th month & $143.24 \pm 36.12$ & $152.00 \pm 17.86$ & 0.099 \\
\hline p-value ${ }^{\mathrm{b}}$ & $0.002^{*}$ & 0.606 & \\
\hline \multicolumn{4}{|c|}{ Inferior nasal sector $\mathrm{pRNFL}$} \\
\hline Baseline & $126.15 \pm 29.88$ & $117.02 \pm 18.83$ & $0.036^{*}$ \\
\hline 6th month & $115.36 \pm 20.87$ & $115.47 \pm 20.03$ & 0.968 \\
\hline 12th month & $112.98 \pm 21.92$ & $115.07 \pm 19.13$ & 0.442 \\
\hline 24th month & $111.50 \pm 20.96$ & $114.80 \pm 20.28$ & 0.267 \\
\hline p-value ${ }^{b}$ & $0.004^{*}$ & 0.172 & \\
\hline \multicolumn{4}{|c|}{ Nasal sector pRNFL } \\
\hline Baseline & $81.70 \pm 17.43$ & $74.20 \pm 11.73$ & $0.004^{*}$ \\
\hline 6th month & $76.11 \pm 12.14$ & $73.73 \pm 12.17$ & 0.158 \\
\hline 12th month & $74.50 \pm 12.08$ & $73.11 \pm 11.58$ & 0.382 \\
\hline 24th month & $74.90 \pm 13.39$ & $73.20 \pm 11.63$ & 0.549 \\
\hline p-value ${ }^{\mathrm{b}}$ & $0.015^{\star}$ & 0.076 & \\
\hline \multicolumn{4}{|c|}{ Superior nasal sector $\mathrm{pRNFL}$} \\
\hline Baseline & $132.80 \pm 33.37$ & $120.35 \pm 25.96$ & $0.011^{*}$ \\
\hline 6th month & $122.53 \pm 26.98$ & $120.42 \pm 22.08$ & 0.572 \\
\hline 12th month & $120.57 \pm 27.26$ & $120.22 \pm 21.53$ & 0.925 \\
\hline 24th month & $119.83 \pm 27.73$ & $118.93 \pm 20.41$ & 0.622 \\
\hline p-value $e^{b}$ & $<0.001^{\star}$ & 0.561 & \\
\hline
\end{tabular}

Table 2. Comparison of peripapillary retinal nerve fiber layer thickness $(\mu \mathrm{m})$ in the unilateral branch retinal

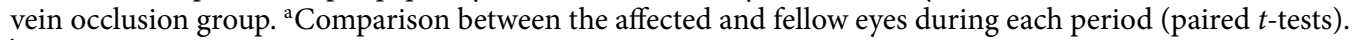
${ }^{\mathrm{b}}$ Comparison between the baseline and 24 -month values (paired $t$-tests). Asterisks $\left({ }^{*}\right)$ indicate statistically significant $\mathrm{p}$-values. $p R N F L$ peripapillary retinal nerve fiber layer.

sector pRNFL thicknesses were significantly different in the fellow eyes of patients with CRVO compared with the fellow eyes of patients with BRVO $(\mathrm{p}=0.038, \mathrm{p}=0.029$, and $\mathrm{p}=0.024$, respectively).

Best-corrected visual acuity, IOP, and central macular thickness variances. In the BRVO group, the best-corrected visual acuity (BCVA) of the affected eyes had improved significantly at 24 months compared to baseline, whereas in the fellow eyes it showed no significant change (Table 5). The BCVA of the affected eyes was lower than that of the fellow eyes at all visits. In the CRVO group, no significant change was observed in BCVA in either the affected or the fellow eyes at 24 months compared to baseline. However, at all visits, the BCVA of the affected eyes was lower than that of the fellow eyes. 


\begin{tabular}{|c|c|c|c|}
\hline & Affected eye & Fellow eye & p-value ${ }^{a}$ \\
\hline \multicolumn{4}{|c|}{ Global pRNFL } \\
\hline Baseline & $136.04 \pm 36.33$ & $99.93 \pm 13.59$ & $<0.001^{*}$ \\
\hline 6th month & $118.46 \pm 34.12$ & $98.81 \pm 14.05$ & $0.005^{*}$ \\
\hline 12th month & $106.50 \pm 18.95$ & $97.00 \pm 14.44$ & $0.001^{*}$ \\
\hline 24th month & $101.48 \pm 25.85$ & $96.36 \pm 14.61$ & 0.254 \\
\hline p-value ${ }^{b}$ & $<0.001^{*}$ & $0.011^{*}$ & \\
\hline \multicolumn{4}{|c|}{ Superior temporal sector pRNFL } \\
\hline Baseline & $168.96 \pm 40.85$ & $138.85 \pm 22.74$ & $<0.001^{\star}$ \\
\hline 6th month & $154.13 \pm 43.15$ & $136.88 \pm 25.88$ & 0.087 \\
\hline 12th month & $143.58 \pm 33.68$ & $133.70 \pm 24.75$ & 0.299 \\
\hline 24th month & $129.08 \pm 37.14$ & $131.12 \pm 26.39$ & 0.804 \\
\hline p-value ${ }^{b}$ & $0.001^{*}$ & $0.003^{*}$ & \\
\hline \multicolumn{4}{|c|}{ Temporal sector $\mathrm{pRNFL}$} \\
\hline Baseline & $127.11 \pm 54.33$ & $76.26 \pm 14.28$ & $<0.001^{\star}$ \\
\hline 6th month & $101.08 \pm 43.76$ & $76.81 \pm 14.24$ & $0.011^{*}$ \\
\hline 12th month & $90.38 \pm 24.55$ & $76.13 \pm 14.73$ & $0.003^{*}$ \\
\hline 24th month & $87.84 \pm 31.98$ & $73.60 \pm 15.02$ & $0.006^{*}$ \\
\hline p-value & $0.002^{\star}$ & 0.361 & \\
\hline \multicolumn{4}{|c|}{ Inferior temporal sector $\mathrm{pRNFL}$} \\
\hline Baseline & $168.70 \pm 53.62$ & $143.41 \pm 28.56$ & $0.012^{*}$ \\
\hline 6th month & $163.29 \pm 38.39$ & $141.77 \pm 26.09$ & $0.002^{*}$ \\
\hline 12th month & $146.29 \pm 37.98$ & $135.87 \pm 24.52$ & 0.201 \\
\hline 24th month & $136.60 \pm 36.58$ & $134.92 \pm 24.70$ & 0.774 \\
\hline p-value & $0.017^{*}$ & $0.022^{*}$ & \\
\hline \multicolumn{4}{|c|}{ Inferior nasal sector pRNFL } \\
\hline Baseline & $147.59 \pm 54.64$ & $106.48 \pm 27.59$ & $0.001^{*}$ \\
\hline 6th month & $128.29 \pm 40.81$ & $105.58 \pm 24.20$ & $0.025^{*}$ \\
\hline 12th month & $113.75 \pm 29.41$ & $99.35 \pm 24.38$ & 0.053 \\
\hline 24th month & $104.32 \pm 21.87$ & $102.48 \pm 24.72$ & 0.758 \\
\hline p-value ${ }^{b}$ & $0.003^{*}$ & 0.094 & \\
\hline \multicolumn{4}{|c|}{ Nasal sector pRNFL } \\
\hline Baseline & $100.96 \pm 43.76$ & $71.78 \pm 16.69$ & $0.001^{*}$ \\
\hline 6th month & $87.63 \pm 35.93$ & $69.81 \pm 18.47$ & $0.026^{*}$ \\
\hline 12th month & $74.67 \pm 20.43$ & $68.61 \pm 17.91$ & 0.134 \\
\hline 24th month & $74.28 \pm 25.60$ & $69.24 \pm 17.29$ & 0.315 \\
\hline p-value ${ }^{b}$ & $0.016^{\star}$ & 0.541 & \\
\hline \multicolumn{4}{|c|}{ Superior nasal sector pRNFL } \\
\hline Baseline & $146.07 \pm 48.54$ & $114.59 \pm 26.45$ & $0.002^{*}$ \\
\hline 6th month & $125.29 \pm 54.52$ & $112.27 \pm 26.19$ & 0.244 \\
\hline 12th month & $117.58 \pm 33.39$ & $109.87 \pm 27.24$ & 0.256 \\
\hline 24th month & $112.16 \pm 38.65$ & $110.52 \pm 25.23$ & 0.804 \\
\hline p-value ${ }^{b}$ & $0.003^{*}$ & 0.115 & \\
\hline
\end{tabular}

Table 3. Comparison of peripapillary retinal nerve fiber layer thickness $(\mu \mathrm{m})$ in the unilateral central retinal vein occlusion group. ${ }^{\mathrm{a} C o m p a r i s o n}$ between affected and fellow eyes in each period (paired $t$-test). ${ }^{\mathrm{b}}$ Comparison between the baseline and 24 -month values (paired $t$-test). Asterisks ${ }^{\star}{ }^{*}$ indicate statistically significant $\mathrm{p}$-values. $p R N F L$ peripapillary retinal nerve fiber layer.

In both RVO groups, there was no significant difference in IOP in either the affected or the fellow eyes at 24 months compared to baseline. Additionally, no significant differences in IOP were observed between the affected and fellow eyes at any of the visits.

In both groups, the central macular thickness (CMT) of the affected eyes decreased significantly at 24 months compared to baseline (BRVO group, $\mathrm{p}<0.001$; CRVO group, $\mathrm{p}=0.001$ ); no difference was observed in the fellow eyes. In both groups, the CMT of the affected eyes was greater than that of the fellow eyes at all visits. 


\begin{tabular}{|c|c|c|c|c|c|c|}
\hline & BRVO group & CRVO group & p-value ${ }^{a}$ & Control & p-value ${ }^{b}$ & p-value ${ }^{c}$ \\
\hline \multicolumn{7}{|l|}{ G pRNFL } \\
\hline Baseline & $104.52 \pm 10.46$ & $99.93 \pm 13.59$ & 0.110 & $103.40 \pm 10.54$ & 0.605 & 0.222 \\
\hline 6th month & $104.07 \pm 10.58$ & $98.81 \pm 14.05$ & 0.079 & $103.39 \pm 9.61$ & 0.765 & 0.126 \\
\hline 12th month & $103.87 \pm 10.33$ & $97.00 \pm 14.44$ & $0.026^{*}$ & $103.29 \pm 10.52$ & 0.789 & $0.041^{\star}$ \\
\hline 24th month & $103.35 \pm 10.21$ & $96.36 \pm 14.61$ & $0.021^{\star}$ & $103.25 \pm 10.62$ & 0.964 & $0.024^{*}$ \\
\hline p-value ${ }^{d}$ & $0.001^{*}$ & $0.011^{\star}$ & & 0.824 & & \\
\hline \multicolumn{7}{|l|}{ ST pRNFL } \\
\hline Baseline & $144.35 \pm 22.64$ & $138.85 \pm 22.74$ & 0.321 & $143.75 \pm 18.95$ & 0.890 & 0.321 \\
\hline 6th month & $145.13 \pm 21.71$ & $136.88 \pm 25.88$ & 0.155 & $145.84 \pm 14.53$ & 0.860 & 0.118 \\
\hline 12th month & $145.04 \pm 21.67$ & $133.70 \pm 24.75$ & 0.055 & $142.63 \pm 19.81$ & 0.573 & 0.106 \\
\hline 24th month & $143.74 \pm 21.11$ & $131.12 \pm 26.39$ & $0.031^{\star}$ & $144.00 \pm 19.94$ & 0.951 & $0.022^{*}$ \\
\hline p-value ${ }^{d}$ & 0.546 & $0.003^{*}$ & & 0.848 & & \\
\hline \multicolumn{7}{|l|}{ T pRNFL } \\
\hline Baseline & $76.85 \pm 12.85$ & $76.26 \pm 14.28$ & 0.857 & $78.38 \pm 11.58$ & 0.546 & 0.488 \\
\hline 6th month & $75.87 \pm 12.32$ & $76.81 \pm 14.24$ & 0.771 & $77.50 \pm 10.08$ & 0.516 & 0.820 \\
\hline 12th month & $75.78 \pm 11.86$ & $76.13 \pm 14.73$ & 0.916 & $79.10 \pm 11.70$ & 0.175 & 0.361 \\
\hline 24th month & $75.67 \pm 11.75$ & $73.60 \pm 15.02$ & 0.522 & $79.08 \pm 11.03$ & 0.150 & 0.080 \\
\hline p-value ${ }^{\mathrm{d}}$ & 0.084 & 0.361 & & 0.125 & & \\
\hline \multicolumn{7}{|l|}{ IT pRNFL } \\
\hline Baseline & $151.26 \pm 19.36$ & $143.41 \pm 28.56$ & 0.166 & $147.06 \pm 27.65$ & 0.398 & 0.589 \\
\hline 6th month & $152.29 \pm 17.25$ & $141.77 \pm 26.09$ & 0.074 & $147.95 \pm 19.27$ & 0.282 & 0.280 \\
\hline 12th month & $151.93 \pm 17.34$ & $135.87 \pm 24.52$ & $0.002^{\star}$ & $150.27 \pm 20.47$ & 0.672 & $0.011^{\star}$ \\
\hline 24th month & $152.00 \pm 17.86$ & $134.92 \pm 24.70$ & $0.004^{*}$ & $150.25 \pm 19.37$ & 0.650 & $0.005^{\star}$ \\
\hline p-value ${ }^{\mathrm{d}}$ & 0.606 & $0.022^{\star}$ & & 0.206 & & \\
\hline \multicolumn{7}{|l|}{ IN pRNFL } \\
\hline Baseline & $117.02 \pm 18.83$ & $106.48 \pm 27.59$ & 0.086 & $114.25 \pm 21.32$ & 0.506 & 0.178 \\
\hline 6th month & $115.47 \pm 20.03$ & $105.58 \pm 24.20$ & 0.068 & $116.55 \pm 21.71$ & 0.813 & 0.063 \\
\hline 12th month & $115.07 \pm 19.13$ & $99.35 \pm 24.38$ & $0.005^{*}$ & $114.23 \pm 21.15$ & 0.841 & $0.010^{*}$ \\
\hline 24th month & $114.80 \pm 20.28$ & $102.48 \pm 24.72$ & $0.027^{\star}$ & $114.23 \pm 21.27$ & 0.894 & $0.038^{*}$ \\
\hline p-value ${ }^{d}$ & 0.172 & 0.094 & & 0.740 & & \\
\hline \multicolumn{7}{|l|}{ N pRNFL } \\
\hline Baseline & $74.20 \pm 11.73$ & $71.78 \pm 16.69$ & 0.511 & $70.40 \pm 11.28$ & 0.113 & 0.703 \\
\hline 6th month & $73.73 \pm 12.17$ & $69.81 \pm 18.47$ & 0.284 & $71.42 \pm 11.38$ & 0.377 & 0.694 \\
\hline 12th month & $73.11 \pm 11.58$ & $68.61 \pm 17.91$ & 0.281 & $71.23 \pm 11.52$ & 0.432 & 0.526 \\
\hline 24th month & $73.20 \pm 11.63$ & $69.24 \pm 17.29$ & 0.255 & $70.37 \pm 11.93$ & 0.249 & 0.743 \\
\hline p-value ${ }^{d}$ & 0.076 & 0.541 & & 0.788 & & \\
\hline \multicolumn{7}{|l|}{ SN pRNFL } \\
\hline Baseline & $120.35 \pm 25.96$ & $114.59 \pm 26.45$ & 0.367 & $121.33 \pm 24.15$ & 0.849 & 0.266 \\
\hline 6th month & $120.42 \pm 22.08$ & $112.27 \pm 26.19$ & 0.166 & $119.82 \pm 22.61$ & 0.902 & 0.223 \\
\hline 12th month & $120.22 \pm 21.53$ & $109.87 \pm 27.24$ & 0.090 & $119.33 \pm 22.84$ & 0.847 & 0.130 \\
\hline 24th month & $118.93 \pm 20.41$ & $110.52 \pm 25.23$ & 0.132 & $119.06 \pm 23.89$ & 0.978 & 0.159 \\
\hline p-value ${ }^{\mathrm{d}}$ & 0.561 & 0.115 & & 0.054 & & \\
\hline
\end{tabular}

Table 4. Comparison of peripapillary retinal nerve fiber layer thickness $(\mu \mathrm{m})$ between fellow eyes and normal control eyes. ${ }^{a}$ Comparison between the BRVO fellow eyes and CRVO fellow eyes in each period (independent samples $t$-test). ${ }^{\mathrm{b}}$ Comparison between the BRVO fellow eyes and normal control eyes (independent samples $t$-test). ${ }^{c}$ Comparison between CRVO fellow eyes and normal control eyes (independent samples $t$-test). ${ }^{\mathrm{d}}$ Comparison between the baseline and 24 -month values (paired $t$-test). Asterisks ${ }^{*}$ ) indicate statistically significant p-values. $p R N F L$ peripapillary retinal nerve fiber layer, $G$ global, $S T$ superior temporal, $T$ temporal, $I T$ inferior temporal, $I N$ inferior nasal, $N$ nasal, $S N$ superior nasal.

\section{Discussion}

To the best of our knowledge, this is the first study to compare longitudinal changes in pRNFL thickness between patients with BRVO and CRVO. We found that global and all-sector pRNFL thicknesses were greater in the affected eyes than in the fellow eyes of patients with these conditions at baseline; however, at 24 months, only the temporal sector of the affected eyes of patients with CRVO remained significantly thicker. Furthermore, the global pRNFL thickness of the fellow eyes decreased significantly at 24 months compared to baseline in the BRVO and CRVO groups, while remaining stable in the normal control group. In addition, we found that the fellow 

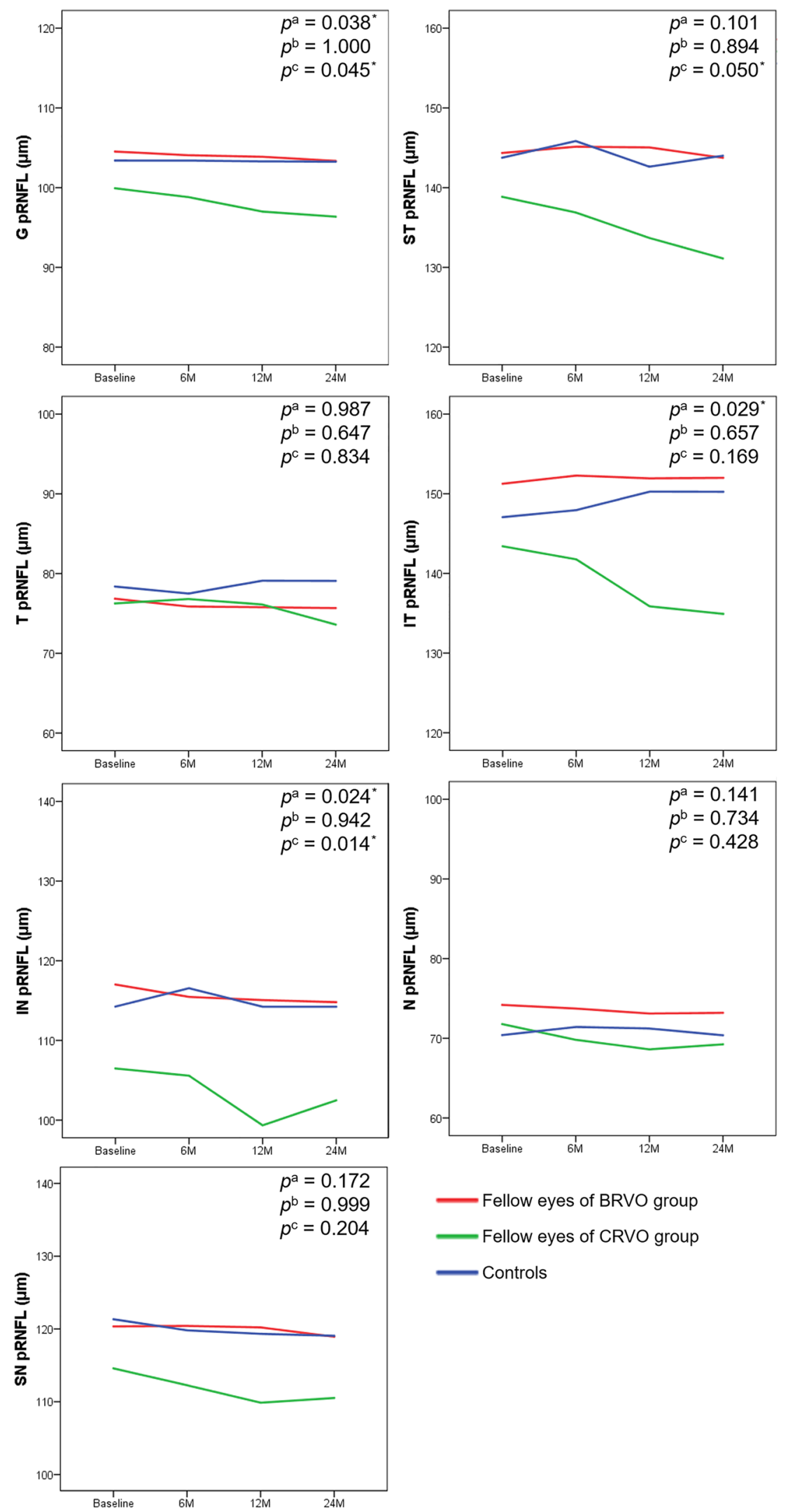

Figure 1. Changes in the peripapillary retinal nerve fiber layer thickness (pRNFL) in fellow eyes and in normal control eyes. The $\mathrm{p}$-values (derived from a repeated measures analysis of variance) are shown for the differences between groups regarding the amount of pRNFL change over time. $\mathrm{p}^{\mathrm{a}}$ Comparison between fellow BRVO and fellow CRVO eyes. $\mathrm{p}^{\mathrm{b}}$ Comparison between fellow BRVO eyes and normal controls. $\mathrm{p}^{c}$ Comparison between fellow CRVO and normal control eyes. G global, $S T$ superior temporal, $T$ temporal, $I T$ inferior temporal, $I N$ inferior nasal, $N$ nasal, $S N$ superior nasal. 


\begin{tabular}{|c|c|c|c|}
\hline & Affected eye & Fellow eye & p-value ${ }^{a}$ \\
\hline \multicolumn{4}{|c|}{ BRVO group } \\
\hline \multicolumn{4}{|c|}{ BCVA (logMAR) } \\
\hline Baseline & $0.46 \pm 0.43$ & $0.04 \pm 0.08$ & $<0.001^{*}$ \\
\hline 6th month & $0.23 \pm 0.32$ & $0.04 \pm 0.08$ & $<0.001^{*}$ \\
\hline 12th month & $0.24 \pm 0.32$ & $0.05 \pm 0.08$ & $<0.001^{\star}$ \\
\hline 24th month & $0.23 \pm 0.29$ & $0.05 \pm 0.07$ & $<0.001^{\star}$ \\
\hline p-value ${ }^{b}$ & $0.001^{\star}$ & 0.431 & \\
\hline \multicolumn{4}{|c|}{ IOP (mmHg) } \\
\hline Baseline & $14.98 \pm 2.93$ & $15.52 \pm 2.92$ & 0.091 \\
\hline 6th month & $14.96 \pm 3.99$ & $15.20 \pm 2.96$ & 0.603 \\
\hline 12th month & $14.63 \pm 3.04$ & $14.29 \pm 2.99$ & 0.253 \\
\hline 24th month & $14.66 \pm 3.21$ & $14.78 \pm 3.38$ & 0.904 \\
\hline p-value ${ }^{b}$ & 0.487 & 0.088 & \\
\hline \multicolumn{4}{|l|}{$\mathrm{CMT}(\mu \mathrm{m})$} \\
\hline Baseline & $468.33 \pm 194.17$ & $262.59 \pm 26.52$ & $<0.001^{*}$ \\
\hline 6th month & $325.93 \pm 130.32$ & $265.15 \pm 26.26$ & $0.004^{*}$ \\
\hline 12th month & $296.30 \pm 80.92$ & $265.11 \pm 28.87$ & $0.017^{\star}$ \\
\hline 24th month & $298.45 \pm 75.54$ & $265.89 \pm 27.17$ & $0.010^{*}$ \\
\hline p-value ${ }^{b}$ & $<0.001^{*}$ & 0.339 & \\
\hline \multicolumn{4}{|l|}{ CRVO group } \\
\hline \multicolumn{4}{|c|}{ BCVA (logMAR) } \\
\hline Baseline & $0.72 \pm 0.72$ & $0.13 \pm 0.19$ & $<0.001^{\star}$ \\
\hline 6th month & $0.57 \pm 0.60$ & $0.12 \pm 0.17$ & $0.001^{*}$ \\
\hline 12th month & $0.54 \pm 0.59$ & $0.12 \pm 0.14$ & $0.002^{*}$ \\
\hline 24th month & $0.66 \pm 0.71$ & $0.13 \pm 0.17$ & $0.001^{*}$ \\
\hline p-value ${ }^{b}$ & 0.517 & 0.937 & \\
\hline \multicolumn{4}{|c|}{ IOP (mmHg) } \\
\hline Baseline & $15.74 \pm 2.98$ & $15.85 \pm 3.02$ & 0.855 \\
\hline 6th month & $16.15 \pm 3.25$ & $16.20 \pm 2.77$ & 0.864 \\
\hline 12th month & $16.50 \pm 3.48$ & $15.84 \pm 3.42$ & 0.270 \\
\hline 24th month & $15.62 \pm 3.48$ & $15.52 \pm 3.00$ & 0.832 \\
\hline p-value ${ }^{b}$ & 0.881 & 0.185 & \\
\hline \multicolumn{4}{|l|}{$\mathrm{CMT}(\mu \mathrm{m})$} \\
\hline Baseline & $563.22 \pm 247.01$ & $264.22 \pm 29.47$ & $<0.001^{*}$ \\
\hline 6th month & $393.92 \pm 195.86$ & $262.78 \pm 24.09$ & $0.003^{\star}$ \\
\hline 12th month & $415.81 \pm 212.94$ & $267.48 \pm 25.82$ & $0.002^{*}$ \\
\hline 24th month & $356.96 \pm 134.09$ & $263.96 \pm 28.31$ & $0.001^{*}$ \\
\hline p-value ${ }^{b}$ & $0.001^{*}$ & 1.000 & \\
\hline
\end{tabular}

Table 5. Best-corrected visual acuity, intraocular pressure, and central macular thickness variances in eyes with retinal vein occlusion. ${ }^{a}$ Comparison between the affected and fellow eyes in each period (paired $t$-test). ${ }^{\mathrm{b}}$ Comparison between the baseline and 24 -month values (paired $t$-test). Asterisks $\left({ }^{*}\right)$ indicate statistically significant $\mathrm{p}$-values. $B R V O$ branch retinal vein occlusion, $C R V O$ central retinal vein occlusion, $B C V A$ bestcorrected visual acuity, $\log M A R$ logarithm of the minimum angle of resolution, $I O P$ intraocular pressure.

eyes of the CRVO group had a significantly lower pRNFL thickness at 12 and 24 months compared to those of the BRVO group and normal controls.

Glaucoma is a progressive optic neuropathy accompanied by morphological abnormalities of the optic disc and surrounding structures. The measurement of pRNFL thickness is useful to confirm structural changes in early glaucoma ${ }^{23,24}$. Additionally, this technique is superior to topographic optic disc assessment in diagnosing glaucoma ${ }^{25,26}$. Considering the irreversible nature of glaucoma, early detection of pRNFL defects is important for a proper evaluation and for initiating treatment in a timely manner.

In this study, global and all-sector pRNFL thicknesses in the affected eyes in both the BRVO and CRVO groups decreased significantly at 24 months and were significantly greater than those of the fellow eyes at baseline. The pRNFL thickness of the affected eyes at baseline was likely to be greater than that of the fellow eye owing to the structural effect of macular edema. In both groups, the pRNFL thickness in the affected eye decreased as the CMT decreased. In this regard, a previous study including patients with diabetic retinopathy and age-related macular degeneration reported that the pRNFL was affected by macular lesions ${ }^{27,28}$. Macular edema due to RVO is known 
to involve the inner layers of retina, as compared to diabetic macular edema ${ }^{29}$. Therefore, it is not surprising that the inner RNFL is predominantly affected in RVO.

In contrast, the pRNFL thickness in the superior temporal sector was lower in the affected eyes than in the fellow eyes of the BRVO group at 12 and 24 months. In a study including 20 patients with unilateral BRVO, the mean RNFL thickness was significantly greater in the affected eyes than in the normal fellow eyes at the first visit and at 1 month, while it was lower at 6 and 12 months ${ }^{18}$. However, they reported that the RNFL thickness of the area opposite to that of BRVO did not change significantly at 12 months and showed no difference in comparison with the fellow eyes ${ }^{18}$. This would suggest that the RNFL becomes thin due to BRVO itself. Similarly, in a histopathologic study of patients with BRVO, Frangieh et al. ${ }^{30}$ reported inner retinal ischemic atrophy in the area of occlusion; the decrease in pRNFL thickness of the affected eyes was also considered to be a result of RNFL atrophy. However, in the present study, there was no sector in which the pRNFL thickness of the affected eyes was lower than that of the fellow eyes of the CRVO group at 24 months. Indeed, the pRNFL thickness of the temporal sector remained significantly greater in the affected eye throughout the entire study period. The CMT of affected eyes of the CRVO group was relatively greater than that of the BRVO group, even at 24 months. As a result, the effect of macular edema on pRNFL seemed to persist for up to 24 months in the CRVO group. Follow-up studies are necessary to confirm if this effect persists after macular edema decreases.

RVO has been associated with glaucoma, and the two diseases share common risk factors such as old age, hypertension, diabetes, cardiovascular disease, and hyperlipidemia ${ }^{11-13,16}$. There are also reports of increased blood and plasma viscosity in patients with RVO and glaucoma ${ }^{31,32}$. Pathophysiological changes in blood vessels caused by these risk factors can have a systemic effect. Therefore, if RVO or glaucoma due to vascular abnormality occurs in one eye, similar changes are likely to occur in the fellow eye. In this study, the fellow eyes of patients with BRVO showed no significant differences in pRNFL at any of the visits compared to those of normal controls. However, global pRNFL thickness decreased significantly in the fellow eyes of patients with BRVO, whereas there was no significant decrease in pRNFL in the normal control eyes at 24 months compared to the baseline. In the fellow eyes of patients with CRVO, the global, superior temporal sector, and inferior temporal sector pRNFL thickness decreased significantly at 24 months. These changes in the fellow eyes of RVO support the hypothesis that systemic pathophysiological vascular abnormalities cause both glaucomatous optic neuropathy and RVO. Additionally, Shin et al. ${ }^{20}$ reported that, compared with normal controls, the fellow eyes of patients with unilateral RVO showed a lower peripapillary vessel density and perfusion density in OCT angiography; furthermore, pRNFL thickness was significantly related to peripapillary vessel density and perfusion density. Insufficient blood flow can cause ischemic damage to the optic nerve tissue and axons and may lead to a decrease in pRNF.

In a previous cross-sectional study, the fellow eyes of patients with unilateral RVO had a lower pRNFL thickness compared to normal controls ${ }^{14,20,21}$. Kim et al. ${ }^{14}$ and Shin et al. ${ }^{20}$ reported that the average, inferior quadrant, and temporal quadrant pRNFL thicknesses were significantly lower in the fellow eyes of patients with unilateral RVO (both BRVO and CRVO) than in normal controls. Additionally, Sirakaya et al..$^{21}$ reported that the average and inferior quadrant pRNFL thickness of the fellow eyes of 35 patients with unilateral BRVO was significantly lower than that of healthy controls. Characteristically, a decrease in inferior quadrant pRNFL thickness was observed in all three previously mentioned studies. The inferior quadrant is the area where glaucoma changes are most commonly observed ${ }^{33}$. A previous study investigating longitudinal changes in the pRNFL thickness of fellow eyes of patients with unilateral RVO (both BRVO and CRVO) reported that the annual reduction rate was greater in the fellow eyes compared to those in normal controls ${ }^{22}$. However, the BRVO and CRVO groups were not analyzed separately, and the CRVO group only included eight eyes. Furthermore, patients were not treatment-naive and the mean pRNFL thickness at baseline seemed to be different between the fellow eyes of patients with RVO $(95.9 \pm 8.0 \mu \mathrm{m})$ and those of normal controls $(98.7 \pm 7.4 \mu \mathrm{m})$. In our study, the global, inferior temporal sector, and inferior nasal sector pRNFL thicknesses at 12 and 24 months were significantly lower in the fellow eyes of patients with CRVO than in both normal controls and fellow eyes of patients with BRVO. Additionally, the reductions in the global, superior temporal sector, inferior temporal sector, and inferior nasal sector pRNFL thicknesses of the fellow eyes of patients with CRVO were greater than those of normal controls and of the fellow eyes of patients with BRVO (Fig. 1). This indicates that the fellow eyes of patients with CRVO are more vulnerable to pRNFL damage.

This study had several limitations, the first of which is its nonrandomized, retrospective design. Second, although we observed a structural change in pRNFL, the result of a visual field test, which measures the corresponding functional change, was not confirmed. Finally, although the prevalence of hypertension and diabetes in the three groups was matched, no data was collected regarding disease severity or specific treatments. It is 
necessary to compare any differences in blood pressure and laboratory data (such as blood glucose, glycated hemoglobin, lipid tests) between the three groups through follow-up prospective studies. Nevertheless, this study provides important information regarding the differences between branch and central RVO and the association of these conditions with glaucoma.

In conclusion, our study showed that the fellow eyes of patients with BRVO and CRVO suffered a reduction in pRNFL thickness compared with normal controls. Additionally, the fellow eyes of patients with CRVO are susceptible to pRNFL damage during the 2 years after the event. These findings suggest that RVO and glaucoma share common systemic pathophysiological vascular abnormalities. Additionally, our findings show that there might be differences in the pathogenic mechanisms of BRVO and CRVO. This suggests that close observation is needed to evaluate the changes in pRNFL in both the affected and fellow eyes of patients with RVO, especially in those with CRVO.

\section{Methods}

Ethics statement. This retrospective, longitudinal, case-control study complied with the tenets of the World Medical Association Declaration of Helsinki. The study and data collection were carried out with approval from the Institutional Review Board (IRB) of Hangil Eye Hospital (IRB number: 21010). The requirement to obtain informed consent from study participants was waived by the Hangil Eye Hospital IRB given the retrospective nature of the study.

Subjects. This study included patients newly diagnosed with unilateral BRVO (BRVO group) or unilateral CRVO (CRVO group) at the Hangil Eye Hospital between April 2015 and June 2018. All patients were diagnosed with RVO using fundus examination, fundus photography, fluorescein angiography, and spectral domain optical coherence tomography (SD-OCT). The normal control group included age-, sex-, and underlying disease (hypertension and diabetes)-matched patients who visited the hospital for an ophthalmic examination within the same period and did not present abnormal findings on fundus examination and SD-OCT.

Patients were excluded if they met any of the following criteria: (1) history of optic nerve disease, such as glaucoma, ischemic optic neuropathy, or optic neuritis; (2) presence of a glaucomatous optic disc (increased cup/ disc ratio, narrowing or notching of the neural rim, or disc hemorrhage); (3) history of other retinal disease or uveitis; (4) history of previous treatments that affect RNFL thickness, including intraocular surgery, intravitreal injection, laser photocoagulation, and glaucoma eye drops; (5) spherical equivalent $> \pm 6.0 \mathrm{D}$; or (6) difficulty in obtaining a clear image owing to significant media opacity.

Ophthalmic examinations. The BCVA and IOP were assessed at baseline and at 6, 12, and 24 months.

The IOP was measured with a noncontact tonometer (NT-530, NIDEK, Aichi, Japan); the average value was measured three times for each eye and was displayed on the machine. pRNFL thickness and CMT were measured using SD-OCT (Spectralis ${ }^{\circ}$ OCT, Heidelberg Engineering, Heidelberg, Germany) and the Spectralis Nsite Axonal Analytics Module (Acquisition software version 6.12.4.0) (Heidelberg Engineering). pRNFL thickness was automatically measured at six sectors (Fig. 2): temporal $\left(315-45^{\circ}\right)$, superior temporal $\left(45-90^{\circ}\right)$, superior nasal $\left(90-135^{\circ}\right)$, nasal $\left(135-225^{\circ}\right)$, inferior nasal $\left(225-270^{\circ}\right)$, and inferior temporal $\left(270-315^{\circ}\right)$. Global RNFL thickness was obtained by averaging $360^{\circ}$ pRNFL thickness measurements.

Statistical analysis. Statistical analyses were performed using the Statistical Package for the Social Sciences software version 23.0 (IBM, Armonk, NY, USA). Results are expressed as mean \pm standard deviation. One-way analysis of variance (ANOVA) or Pearson's chi-square test were performed to compare the demographics and characteristics among the three groups. Comparisons between the affected and fellow eyes were conducted using paired $t$-tests. Changes in values between baseline and 24-month follow-up examinations were analyzed using a paired $t$-test. An independent samples $t$-test was used to compare pRNFL thickness between the fellow eyes of patients with unilateral RVO and the eyes of normal controls. A repeated-measures ANOVA was used to compare the differences between groups regarding pRNFL changes over time. Statistical significance was set at $\mathrm{p}<0.05$. 


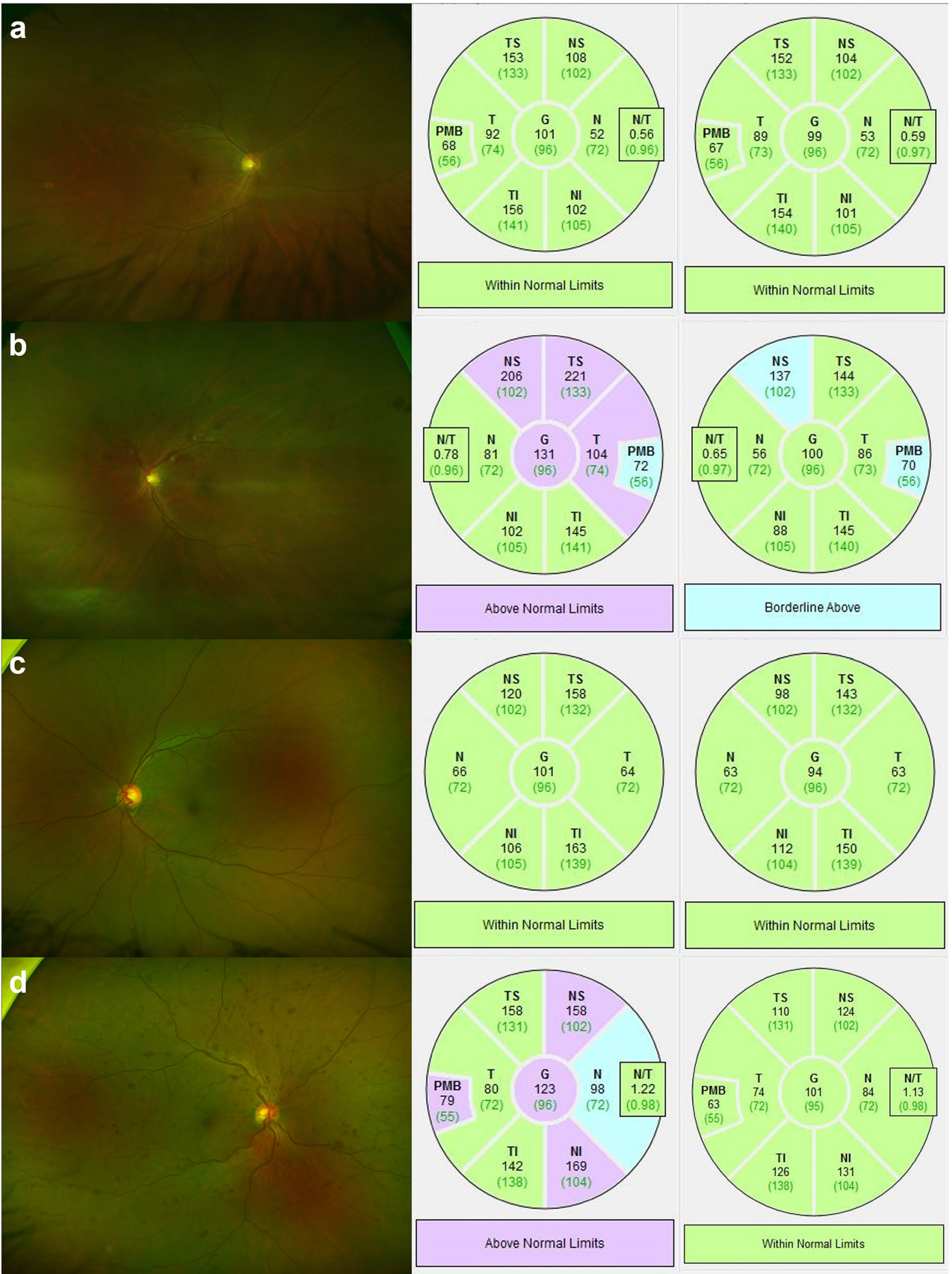

Figure 2. Wide fundus photographs at baseline and peripapillary retinal nerve fiber layer (pRNFL) thickness analysis at baseline and after 24 months. (a) The fellow eye of a patient with unilateral branch retinal vein occlusion (BRVO). (b) The affected eye of the same patient with BRVO. (c) The fellow eye of a patient with unilateral central retinal vein occlusion (CRVO). (d) The affected eye of the same patient with CRVO. The global pRNFL thickness of the BRVO fellow eye decreased by $2 \mu \mathrm{m}$ over 2 years, and that of the CRVO fellow eye decreased by $7 \mu \mathrm{m}$. The pRNFL thickness of the affected eye was higher at baseline both in patients with BRVO and CRVO, and the pRNFL thickness of patients with BRVO was characteristically high in the occluded vascular area. G global, TS temporal superior, $T$ temporal, $T I$ temporal inferior, $N I$ nasal inferior, $N$ nasal, $N S$ nasal superior. 


\section{Data availability}

The datasets used and/or analyzed during the current study are available from the corresponding author on reasonable request.

Received: 19 May 2021; Accepted: 23 August 2021

Published online: 13 September 2021

\section{References}

1. Jaulim, A., Ahmed, B., Khanam, T. \& Chatziralli, I. P. Branch retinal vein occlusion: epidemiology, pathogenesis, risk factors, clinical features, diagnosis, and complications. An update of the literature. Retina 33, 901-910. https://doi.org/10.1097/IAE.0b013e3182 870c15 (2013).

2. Pulido, J. S. et al. Retinal vein occlusions preferred practice pattern $\left(^{\oplus}\right)$ guidelines. Ophthalmology 123, 182-208. https://doi.org/ 10.1016/j.ophtha.2015.10.045 (2016).

3. Zhou, J. Q. et al. The 10-year incidence and risk factors of retinal vein occlusion: The Beijing eye study. Ophthalmology 120, 803-808. https://doi.org/10.1016/j.ophtha.2012.09.033 (2013).

4. Klein, R., Moss, S. E., Meuer, S. M. \& Klein, B. E. The 15-year cumulative incidence of retinal vein occlusion: The beaver dam eye study. Arch. Ophthalmol. 126, 513-518. https://doi.org/10.1001/archopht.126.4.513 (2008).

5. Rogers, S. L. et al. Natural history of branch retinal vein occlusion: An evidence-based systematic review. Ophthalmology 117, 1094-1101. https://doi.org/10.1016/j.ophtha.2010.01.058 (2010).

6. Hayreh, S. S., Zimmerman, M. B. \& Podhajsky, P. Incidence of various types of retinal vein occlusion and their recurrence and demographic characteristics. Am. J. Ophthalmol. 117, 429-441. https://doi.org/10.1016/s0002-9394(14)70001-7 (1994).

7. Hayreh, S. S., Zimmerman, M. B., Beri, M. \& Podhajsky, P. Intraocular pressure abnormalities associated with central and hemicentral retinal vein occlusion. Ophthalmology 111, 133-141. https://doi.org/10.1016/j.ophtha.2003.03.002 (2004).

8. Sperduto, R. D. et al. Risk factors for hemiretinal vein occlusion: Comparison with risk factors for central and branch retinal vein occlusion: The eye disease case-control study. Ophthalmology 105, 765-771. https://doi.org/10.1016/s0161-6420(98)95012-6 (1998).

9. Frucht, J., Shapiro, A. \& Merin, S. Intraocular pressure in retinal vein occlusion. Br. J. Ophthalmol. 68, 26-28. https://doi.org/10. 1136/bjo.68.1.26 (1984).

10. Luntz, M. H. \& Schenker, H. I. Retinal vascular accidents in glaucoma and ocular hypertension. Surv. Ophthalmol. 25, $163-167$. https://doi.org/10.1016/0039-6257(80)90093-4 (1980).

11. Rath, E. Z., Frank, R. N., Shin, D. H. \& Kim, C. Risk factors for retinal vein occlusions. A case-control study. Ophthalmology 99 , 509-514. https://doi.org/10.1016/s0161-6420(92)31940-2 (1992).

12. Risk factors for branch retinal vein occlusion. The eye disease case-control study group. Am. J. Ophthalmol. 116, 286-296 (1993).

13. Risk factors for central retinal vein occlusion. The eye disease case-control study group. Arch. Ophthalmol. 114, 545-554 (1996).

14. Kim, M. J., Woo, S. J., Park, K. H. \& Kim, T. W. Retinal nerve fiber layer thickness is decreased in the fellow eyes of patients with unilateral retinal vein occlusion. Ophthalmology 118, 706-710. https://doi.org/10.1016/j.ophtha.2010.08.028 (2011).

15. Lopilly Park, H. Y., Jeon, S., Lee, M. Y. \& Park, C. K. Glaucoma progression in the unaffected fellow eye of glaucoma patients who developed unilateral branch retinal vein occlusion. Am. J. Ophthalmol. 175, 194-200. https://doi.org/10.1016/j.ajo.2016.10.009 (2017).

16. Bonovas, S., Peponis, V. \& Filioussi, K. Diabetes mellitus as a risk factor for primary open-angle glaucoma: a meta-analysis. Diabet. Med. 21, 609-614. https://doi.org/10.1111/j.1464-5491.2004.01173.x (2004).

17. Stewart, R. M. \& Clearkin, L. G. Insulin resistance and autoregulatory dysfunction in glaucoma and retinal vein occlusion. Am. J. Ophthalmol. 145, 394-396. https://doi.org/10.1016/j.ajo.2007.11.005 (2008).

18. Kim, C. S., Shin, K. S., Lee, H. J., Jo, Y. J. \& Kim, J. Y. Sectoral retinal nerve fiber layer thinning in branch retinal vein occlusion. Retina 34, 525-530. https://doi.org/10.1097/IAE.0b013e3182a2e746 (2014).

19. Lim, H. B., Kim, M. S., Jo, Y. J. \& Kim, J. Y. Prediction of retinal ischemia in branch retinal vein occlusion: Spectral-domain optical coherence tomography study. Invest. Ophthalmol. Vis. Sci. 56, 6622-6629. https://doi.org/10.1167/iovs.15-17678 (2015).

20. Shin, Y. I. et al. Changes in peripapillary microvasculature and retinal thickness in the fellow eyes of patients with unilateral retinal vein occlusion: an OCTA study. Invest. Ophthalmol. Vis. Sci. 60, 823-829. https://doi.org/10.1167/iovs.18-26288 (2019).

21. Sirakaya, E. \& Kucuk, B. Thickness of the lamina cribrosa, retinal-nerve fiber layer, and peripapillary choroid in patients with branch retinal vein occlusion. Ophthalmologica 243, 288-296. https://doi.org/10.1159/000505100 (2020).

22. Shin, Y. I., Lim, H. B., Koo, H., Lee, W. H. \& Kim, J. Y. Longitudinal changes in the peripapillary retinal nerve fiber layer thickness in the fellow eyes of unilateral retinal vein occlusion. Sci. Rep. 10, 7708. https://doi.org/10.1038/s41598-020-64484-5 (2020).

23. Wollstein, G. et al. Optical coherence tomography (OCT) macular and peripapillary retinal nerve fiber layer measurements and automated visual fields. Am. J. Ophthalmol. 138, 218-225. https://doi.org/10.1016/j.ajo.2004.03.019 (2004)

24. Nakatani, Y., Higashide, T., Ohkubo, S., Takeda, H. \& Sugiyama, K. Evaluation of macular thickness and peripapillary retinal nerve fiber layer thickness for detection of early glaucoma using spectral domain optical coherence tomography. J. Glaucoma. 20, 252-259. https://doi.org/10.1097/IJG.0b013e3181e079ed (2011).

25. Medeiros, F. A. et al. Comparison of retinal nerve fiber layer and optic disc imaging for diagnosing glaucoma in patients suspected of having the disease. Ophthalmology 115, 1340-1346. https://doi.org/10.1016/j.ophtha.2007.11.008 (2008).

26. Leung, C. K. et al. American Chinese glaucoma imaging study: A comparison of the optic disc and retinal nerve fiber layer in detecting glaucomatous damage. Invest. Ophthalmol. Vis. Sci. 48, 2644-2652. https://doi.org/10.1167/iovs.06-1332 (2007).

27. Hwang, D. J., Lee, E. J., Lee, S. Y., Park, K. H. \& Woo, S. J. Effect of diabetic macular edema on peripapillary retinal nerve fiber layer thickness profiles. Invest. Ophthalmol. Vis. Sci. 55, 4213-4219. https://doi.org/10.1167/iovs.13-13776 (2014).

28. Jo, Y. J., Kim, W. J., Shin, I. H. \& Kim, J. Y. Longitudinal changes in retinal nerve fiber layer thickness after intravitreal anti-vascular endothelial growth factor therapy. Korean. J. Ophthalmol. 30, 114-120. https://doi.org/10.3341/kjo.2016.30.2.114 (2016).

29. Munk, M. R. et al. Differential diagnosis of macular edema of different pathophysiologic origins by spectral domain optical coherence tomography. Retina 34, 2218-2232. https://doi.org/10.1097/iae.0000000000000228 (2014).

30. Frangieh, G. T., Green, W. R., Barraquer-Somers, E. \& Finkelstein, D. Histopathologic study of nine branch retinal vein occlusions. Arch. Ophthalmol. 100, 1132-1140. https://doi.org/10.1001/archopht.1982.01030040110020 (1982).

31. Sofi, F. et al. Role of haemorheological factors in patients with retinal vein occlusion. Thromb. Haemost. 98, 1215-1219 (2007).

32. Klaver, J. H., Greve, E. L., Goslinga, H., Geijssen, H. C. \& Heuvelmans, J. H. Blood and plasma viscosity measurements in patients with glaucoma. Br. J. Ophthalmol. 69, 765-770. https://doi.org/10.1136/bjo.69.10.765 (1985).

33. Leung, C. K. et al. Comparison of macular and peripapillary measurements for the detection of glaucoma: An optical coherence tomography study. Ophthalmology 112,391-400. https://doi.org/10.1016/j.ophtha.2004.10.020 (2005).

\section{Acknowledgements}

None. 


\section{Author contributions}

J.A. contributed to the conception and design of the study, the acquisition and analysis of the data, and the writing (original draft). D.D.H. contributed to the conception and design of the study, interpretation of the data, and the writing (review and editing). Both authors read and approved the final manuscript.

\section{Competing interests}

The authors declare no competing interests.

\section{Additional information}

Correspondence and requests for materials should be addressed to D.D.-J.H.

Reprints and permissions information is available at www.nature.com/reprints.

Publisher's note Springer Nature remains neutral with regard to jurisdictional claims in published maps and institutional affiliations.

(c) (i) Open Access This article is licensed under a Creative Commons Attribution 4.0 International License, which permits use, sharing, adaptation, distribution and reproduction in any medium or format, as long as you give appropriate credit to the original author(s) and the source, provide a link to the Creative Commons licence, and indicate if changes were made. The images or other third party material in this article are included in the article's Creative Commons licence, unless indicated otherwise in a credit line to the material. If material is not included in the article's Creative Commons licence and your intended use is not permitted by statutory regulation or exceeds the permitted use, you will need to obtain permission directly from the copyright holder. To view a copy of this licence, visit http://creativecommons.org/licenses/by/4.0/.

(C) The Author(s) 2021 